This item was submitted to Loughborough's Research Repository by the author.

Items in Figshare are protected by copyright, with all rights reserved, unless otherwise indicated.

\title{
Learning from difference and similarity: Identities and relational reflexive learning
}

PLEASE CITE THE PUBLISHED VERSION

https://doi.org/10.1177/13505076211038900

PUBLISHER

SAGE Publications

VERSION

VoR (Version of Record)

\section{PUBLISHER STATEMENT}

This is an Open Access Article. It is published by SAGE Publications under the Creative Commons AttributionNonCommercial 4.0 International Licence (CC BY-NC 4.0). Full details of this licence are available at: https://creativecommons.org/licenses/by-nc/4.0/

\section{LICENCE}

CC BY-NC 4.0

\section{REPOSITORY RECORD}

Beech, Nic, Andrew D Brown, Christine Coupland, and Leanne Cutcher. 2021. "Learning from Difference and Similarity: Identities and Relational Reflexive Learning”. Loughborough University. https://hdl.handle.net/2134/16620490.v1. 


\title{
Learning from difference and similarity: Identities and relational reflexive learning
}

\author{
Nic Beech*
}

Middlesex University, UK

\section{Andrew D Brown}

University of Bath, UK

\section{Christine Coupland \\ Loughborough University, UK}

\section{Leanne Cutcher}

The University of Sydney, Australia

\begin{abstract}
Within organizations there is reciprocal interplay between identity construction and learning. Processes of learning are enabled and constrained by identity practices; concomitantly, the possibilities for learning are shaped by the identity positions available to individuals. There is a dynamic between the impositions of organizations and people's freedom to shape their identities and learning plays a crucial role in this. Our purpose in this special issue is to contribute to the understanding of the intersection of identity work and learning as a response to experiences of being different. Experiences of difference include moving into a new role, encountering a disjuncture with others while in a role or a difference in broader life which is reacted to as if it were a problem in an organizational setting. Being different produces a variety of challenges and the papers in this special issue trace how people cope with vulnerabilities, develop resilience and often collaborate in their learning. We focus on how people reflect on their own identity and learn and how, by learning together with people who have similar experiences, micro-communities can support, develop and enhance their insight and identity-positions.
\end{abstract}

\section{Keywords}

Identity, identity work, learning, managerial identities

*The authors are presented in alphabetical surname order to indicate their equal contribution to the paper.

\section{Corresponding author:}

Nic Beech, Middlesex University, The Burroughs, London, NW4 4BT, UK.

Email: n.beech@mdx.ac.uk 


\section{Introduction}

Identities are continuously under construction and actively worked on throughout our organizational lives (Alvesson et al., 2008; Brown, 2015; Ybema et al., 2009). Identity construction is grounded in processes of learning as people recognize and adapt to social expectations and cultural norms. A considerable amount of learning occurs as people seek to fit-in and not be different. Alternatively, or perhaps sometimes concomitantly, we may seek to resist imposed identities and expectations and assert constructions of the self that do not fit-in, and this too entails learning. In many organizational settings, being different may not be an easy experience, especially where dominant, normative narratives of the 'right sort' of identity define the Other as different. In such circumstances, being different is militated against by exclusionary practices which can separate people from position, advantage and privilege (Foucault, 1977; cf. Thornborrow and Brown, 2009). Being different has consequences and learning lies at the heart of how people cope and seek to bring about change personally and collectively.

There is a reciprocal interplay between identity construction and learning. Learning can be a process of identity regulation which ensures that individuals know who they should be and how they ought to act (Coupland et al., 2019). Our purpose in this special issue is to contribute to the understanding of the intersection of identity work and learning as a response to experiences of being different. In this introductory paper, we contribute to this overall objective by examining the potential interplay between the identity and learning literatures in relation to difference. Drawing on Engeström's $(1987,2018)$ theory of expansive learning we pose a set of core questions central to understanding this phenomenon. We explore the literature on identity construction and identity work, deriving a compatible set of questions. Combining these two sets of questions provides a framework for analysing the intersection of identity construction and learning from difference. We use this framework to highlight the contributions of the papers in the special issue before closing with some thoughts regarding future research.

\section{Difference and contradiction at the intersection of learning and identity}

Bateson (1972) distinguished three modes of learning. In Learning I the learner acquires the knowledge or skill to be able to provide the right answer in a context, for example giving the correct answer in a classroom or as a newly promoted manager. Learning II occurs while Learning I is happening and pertains to learning the rules and norms of the context or culture, for example, learning the 'hidden curriculum' of how to please the teacher or join a peer-group or how to use new positional authority as a manager with former colleagues. Typically, such learning incorporates contradictory demands. For example, in a classroom both giving the right answer with enthusiasm and avoiding being excluded by the group as a 'swot', or when being promoted to a managerial position both being expected to be objective and not have favourites whilst former friends and colleagues seek on-going friendship or personal advantage. Learning III involves a systemic shift in which people collectively react to contradictions and seek to reshape their context.

Engeström (1987) builds on Bateson's (1972) work and develops an activity theory perspective on expansive learning. He defines expansive learning as the capacity of learners to reinterpret and expand the purpose and practice of their activity in enriched ways. For Engestrom, a theory of learning must answer four fundamental questions: Who are the subjects of learning? Why do they learn? What do they learn? and How do they learn? In answering the first question, which is one of identity, Engestrom, like Leont'ev (1981), rejects the idea of the individual as the primary unit of 
analysis in learning. Adapting Bakhtin's (1981) dialogical approach, Engestrom regards learning as a fundamentally collective endeavour in which interaction is crucial. This can be seen in each of Bateson's modes of learning and relates not just to who people are as they embark on learning, but whom they are becoming as they learn. For example, managers learning to fit-in as expatriates in multinational companies (Armstrong and Li, 2017) or women learning to fit into a masculine managerial norm (Bryans and Mavin, 2003). From a unitarist perspective, such learning is about adopting a unified organizational purpose, characterized by shared interests (Greenwood and Van Buren, 2017), but for Engeström (2018) although learning is a collective endeavour, it is not based on harmonious and unified experience. Rather it is triggered by contradictions which are the core motivation for people to learn.

Contradictions can arise within groups or communities (or 'activity systems' in Engestrom's terms), for example, as hospital medics seek to apply disease-centred care pathways to patients who have multiple or unresolved diagnoses which mean that they do not fit with the pathway. Similarly, contradictions arise as different activity systems encounter each other, for example when problems occur in coordinating patient discharge from hospitals as the differences between hospital and social care cultures interact (Greig et al., 2012). Such contradictions and differences are more frequent and emphatic with decreased stability in organizational structures and increasing uncertainty (Blackler and Regan, 2009) which impact on people's sense of self as they learn (Beech, 2017) and adapt in turbulent circumstances (Greenberg and Hibbert, 2020).

While diversity identity characteristics are less discussed in the expansive learning literature, they do feature in other parts of the learning literature. For example, Burnham et al. (2008) have developed a model for facilitating groups of family therapeutic practitioners to discuss their differences in terms of gender, race, religion, class, culture and sexuality as part of developing how they will deal with such differences with clients in their own practice. This approach is highly reflexive and is relevant for the management learning literature and the papers in this special issue in particular.

Scholarship focused on self-identities in and around organizations continues apace. A plethora of identities-related special issues (Alvesson et al., 2008; Corlett et al., 2017; Coupland and Brown, 2012; Ybema et al., 2009), conceptual and critical reviews (Ashforth and Schinoff, 2016; Brown, 2015; Caza et al., 2018) and a recent handbook (Brown, 2020) have helped to consolidate a field that not so long ago was regarded as being in need of synthesis (Cerulo, 1997: 400).

Identities are most often regarded as 'the meanings that individuals attach reflexively to themselves' (Brown, 2015: 23). Researchers have sought to explore these subjectively construed meanings in the form of answers to existential questions ranging from 'who am I?' and 'how should I act?' to 'who might I have become?', 'who is it still possible for me to be?' and 'who do I want to become?' The term 'self' is generally regarded as the capacity for reflexive thinking associated with a personal awareness of continuity over time (Blumer, 1969; Giddens, 1991; Mead, 1934). Mostly under the umbrella concepts 'identity work' and 'identity construction' considerable attention has focused on those processes - discursive, dramaturgical, socio-cognitive, symbolic and psychodynamic - by which identities are constructed (Brown, 2017). Initially defined by Snow and Anderson (1987: 1348) as 'the range of activities individuals engage in to create, present and sustain personal identities that are congruent with and supportive of the self-concept', identity work has subsequently been re-imagined as a construct, metaphor and the inspiration for a nascent perspective (Brown, 2021; Caza et al., 2018; Watson, 2008).

Identities and identity work are key to understanding a wide range of processes of organizing and organizational outcomes. Phillips and Hardy (2002: 52) for example, maintain 'we cannot understand processes of organizing unless we understand identity'. At an individual-level issues of identity and identity work have been discussed frequently in relation to, inter alia, identification 
(Ashforth and Mael, 1989), role transitions (Ibarra, 1999), reflexivity (Cutcher, 2020), leadership (DeRue and Ashford, 2010; Brown et al., 2021) and sensemaking (Vough et al., 2020). Some attention has focused on the reciprocal interplay between identities, the processes of their construction (at different levels of analysis) and learning, often with reference to the contexts and especially the relations of power, in which they feature (e.g. Beech et al., 2016; Riach and Cutcher, 2014).

Identity work entails personal change within social contexts structured by relations of power (Foucault, 1977). Central to this is understanding the similarities and differences between the self and others, and the self in relation to context. This type of learning is founded in reflexivity in which there is a recognition of the self and potentially a critical engagement with the self or others/ the context. In some cases, this can lead to identity work in which the self is changed - either to fit-in or to produce an acceptable version of the self which means that potential negative consequences associated with being different are minimized. In other cases, differences between the self and others/the context are valued by the self and in these instances, learning may result in maintaining or amplifying those differences.

Illeris (2014) has argued for a reconceptualization of transformative learning which can be related to identity work, although it is not directly referred to. He argues that such learning is broader than purely cognitive in that it includes and responds to emotional and social conditions and consequently argues that transformative learning "should be defined by the term "identity" (Illeris, 2014: 148). Illeris (2014) calls for further research which illuminates this identity-learning intersection empirically and conceptually and Management Learning has been particularly influential in promoting work that demonstrates the often intimate and nuanced ways that identities inform and are informed by processes of learning (e.g. Gagnon, 2008). Handley et al. (2007: 173), for example, show 'how management consultants learn the practices and identities appropriate to client-consultant projects.' Through a longitudinal study of six managers, Bolander et al. (2019: 283 ) investigate how becoming a manager involves 'the significant work of finding new answers to questions of who one is'. Their research 'underscores the significance of identity work for manager learning' (p. 298). Warhurst's (2011: 274) study using MBA manager-students focuses on how 'most respondents appeared to be actively engaged in various forms of identity-work' drawing on the linguistic resources provided by the programmes of study in which they are enrolled. In a relatively rare paper that 'demonstrates the centrality of emotions to identity work processes' Hay (2014: 519) argues that an appreciation of identity construction is vital to understand and research management education. Much of this work is sophisticatedly reflexive but while some of it analyses or is sensitive to issues of identity and learning with respect to notions of 'difference' (e.g. Bryans and Mavin, 2003; Iszatt-White et al., 2017; McDonald, 2013) a specific focus on difference at the heart of learning and identity construction has to date not been fully explored in the literature and this special issue seeks to address this directly.

In summary, we can derive compatible questions from the expansive learning and identity work literatures. The identity literature is concerned with how people answer existential questions such as 'who am I?' In the learning literature this relates to the question posed by Engeström (2018): 'who is the learner?' In this special issue, we are particularly interested in how people engage in this identity-construction and learning process through being different. The basic existential question is constituted as 'how am I (or we) different to others or the normative expectations of the role I am in?' In the identity literature, this prompts the question: 'who do I want to become?' and in the learning literature 'what am I learning about who I want to become?' (a version of Bateson's (1972) learning II). Although in both literatures there are discussions about fitting in, adopting 'appropriate' subjectivities and conformity, for the papers in this special issue, influenced by both a critical perspective and a focus on change, (Bell and Bridgman, 2017) two questions are prompted: 'what do I (we) want to do about the difference?' and 'what might be needed from others and the 
organization?' Answering these questions led us to consider processes such as: 'how is my identity forming?' and 'how am I learning?' In both literatures, reflexivity is a crucial process in which a person becomes critically aware of their self, others and the context (Cunliffe, 2002) and is active in learning for change (Hibbert et al., 2021). In the next section, we use these framing questions to discuss the collective contributions of the papers in this special issue.

\section{Learning from identity differences: Contributions of the papers in this special issue}

Ligorio (2010) identifies three contexts in which learning and identity change, or 'innovation of the self' (Ligorio, 2010: 95) can be interwoven. The contexts entail 'position' changes which can relate to jobs, roles or personal positions. The three contexts are: moving into a new position; a background position becoming foregrounded; two positions being foregrounded such that a new hybrid position is adopted. The modes of change discussed in this special issue do not map onto Ligorio's framing exactly, but there are notable similarities in the modes of identity dynamics which are particularly pertinent to management and organization-based learning. These are: first, people changing organizational role in a way which significantly impacts on their identity, for example becoming an academic or a manager for the first time, topics that are addressed by Callagher et al. (2021), Weatherall and Ahuja (2021) and Corlett et al. (2021). Secondly, a difference that becomes newly experienced with personal impact and emotion within a specific work context, for example, a clash of ethical positions or a fundamental disagreement about purpose, and this is explored with empirical examples later in this introductory paper. Thirdly, a difference that is experienced as part of broader life, which is reacted to in the workplace, for example, difference experienced through ethnicity, gender, sexuality or because of long-term health challenges, topics that are discussed by Weatherall and Ahuja (2021) and Elraz and Knights (2021). Whether because of the work-identity changing in a significant way, a difference revealed because of an experience at work or part of one's life identity becoming highlighted in the workplace, there is, as Weatherall and Ahuja put it, an experience of being out-of-step or wrong-footed. This tension can stimulate both learning I and II (Bateson, 1972) as people work out what they are meant to know (e.g. the significance of particular types of publishing as an early career researcher, ECR) and the way of being (e.g. how ECRs should respond to established academics). An expectation of organization-centric and unitarist approaches to learning (Greenwood and Van Buren, 2017) is that this learning enables people to be competent and fit-in. However, in the cases discussed here a more critical perspective is taken, considering how difference may be valued, preserved (overtly or covertly) and potentially how organizations might change to learn from difference rather than expecting or requiring conformity.

We have identified core questions which link the learning and identity work literatures and there are certain patterns in how the papers in this special issue address them (implicitly or explicitly). In addressing the 'who am I/who is the learner?' question, the answers are that the subjects are not what is expected or assumed to be normal in the role or the organization. Therefore, there is a significant experience of difference which can introduce contradictions (e.g. being a senior manager but also being vulnerable; Corlett et al., 2021) or tensions (e.g. being an ECR but having 'absent pasts'; Weatherall and Ahuja, 2021). Answering the questions 'what am I learning about what I want to become, and what do I want to do about it?' the papers explore the difficulties of learning and identity work in such situations. For example, some approaches include disguising or 'normalizing' mental health conditions which are stigmatized (Elraz and Knights, 2021), faking managerial confidence (Corlett et al., 2021) or complying with performance expectations (Callagher et al., 
2021). It is noticeable that in general learning and identity work are undertaken by the individual and it might be argued that their organizations and others in the context could also be more adaptive to difference. The answers to the question of how identity work and learning proceed predominantly show the processes to be informal and interactional. Although formal processes such as courses and induction programmes and semi-structured learning methods such as Action Learning feature in these accounts, much of the significant learning occurs in self-organized groups and informal settings. This might be because participants were cautious about expressing vulnerabilities outside high trust contexts. In some cases, informal collective learning helped people resist or challenge the negative consequences of being different, although there is little evidence of organizational learning and change in response. Rather, in at least one case (Callagher et al., 2021), people learning to cope enabled discrimination and other negative issues to continue unchallenged.

Two of the papers in this special issue are based upon studies of ECRs. Weatherall and Ahuja (2021), use a collaborative auto-ethnography to understand being different as a temporal issue and utilizes queer time as a concept to consider how newcomers learn (not) to belong to academia. The authors suggest that learning as a newcomer may be better understood as moments of friction and opportunity rather than linear progression. Temporal orderings for ECRs are imbued with considerations of what progress is required and in what time frame. This presents a normative set of anticipations that differentiate those who do not meet the prescribed expectations from those who do. The authors propose that queer theory offers an opportunity to reframe the process of becoming an academic as a movement that is in friction with normative expectations, acknowledges discontinuous opportunity and allows for other versions of time and identities. The study makes an important contribution through an illustration of how newcomers may learn their identities differently. Absent pasts and vague futures contribute to an experience of being out of step, but perhaps with the potential to construct alternative identities that could create a more enlightened and inclusive academic identity.

The second paper from Callagher et al. (2021) investigates how discrimination poses identity threats in terms of being perceived as different. An autoethnographic approach is used here too as a group of non-white, minority and immigrant ECRs describe the shared space in which they talk about their strategies to fit-in. The group, which is described as providing a shared emotional shelter for one another, can be seen to have other consequences for its members. The process by which their collective anticipatory responses to expected discrimination leads to discrimination being unchallenged and amplified is analysed. This poses critical challenges for workplaces such as universities and business schools. It is noted that in certain settings people's identity work provides strategies to cope with discrimination - which include hiding or faking identities - that may exacerbate rather than challenge the problem of discrimination.

The third paper by Corlett et al. (2021) considers the value of expressing vulnerability as a contrast to the dominant managerial and leadership discourses of being strong, in control and knowledgeable (Corlett et al., 2019). Following a study of senior executives taking part in action learning sets on an executive Masters programme, the participants articulate how they learn to be different to normative leader and organizational expectations. The action learning set environment is described as a 'safe enough' space in which to express vulnerability. Subsequent engagement beyond the classroom environment in their workplaces is described both as dropping the mask and holding the mask. An outcome of the executives' learning experience included a new understanding of expressing vulnerability as positive rather than confirming the dominant understanding of leader vulnerability as negative. Operationalizing that new understanding beyond the classroom into the workplace raises issues around agency and contextual nuance. This surfaces the important question whether learning to be different as a leader in the classroom context could be regarded as 
a form of self-regulation, or self-awareness, or an opportunity to raise consciousness that provides options around how to 'be'.

The final paper by Elraz and Knights (2021) uses vignettes to illustrate how individuals experiencing mental health conditions (MHCs) seek to suppress exhibiting their conditions while 'normalizing' their identities at work. Participants' strategies include, managing their condition by fitting in at work, concealing their symptoms and maintaining stability. The participants articulate a stigmatized identity through their MHC in the research interactions, and at the same time describe their efforts to present a 'normal' self while at work. It is argued that those who do not seek to 'normalize' their identities are likely to suffer further marginalization. Tensions surfaced in the analysis as attachments to a 'normalized' identity may be a cause of further ill-health. Furthermore, disclosure of an MHC (before and during employment) is regarded as potentially introducing negative risks for work opportunities, relationships and future prospects. An important contribution of the paper is that it provides an illustration of how the participants' efforts to fit-in, working on the self while at work, ensures employment, but does not accommodate the potential difficulties posed to individuals with MHCs.

In each setting, identity differences produce a level of risk, vulnerability, stigma, danger or threat: leaders trying out their new vulnerability in a practitioner environment; disclosure of an $\mathrm{MHC}$; members of an ethic minority group calling out discriminatory activities and being out of step in terms of age, ethnicity, familial status and sexuality. Motivations to learn may arise in 'arresting moments' (Greig et al., 2013) when the self is engaged in a social encounter in a repositioning in which the learning is an innovation of the self (Ligorio, 2010) which makes the difference unmistakable, at least to an individual. Beyond this initial reflexive learning, however, generally more positive learning occurs in close contact with others who often share an identity characteristic involving difference from the norm. In each case, time was significant, and it is apparent that there are consequences around the timing of learning to not be different and efforts to fit-in.

\section{Concluding remarks}

Our purpose in this special issue is to contribute to the understanding of the complex intersection of identity work and learning that are responses to experiences of being different. Our view (Coupland et al., 2019) is that better understanding how learning and identity work intersect is important both theoretically and practically. In this introductory paper, we have sought to map out a way of understanding the potential intersection, particularly focusing on the role of difference in learning and identity processes. The literature on expansive learning focuses on contradictions and processes that impact on identity (Engeström, 2018; Illeris, 2014; Ligorio, 2010) but little or no application is made of these innovations in the identity work literature. Equally, advances in the understanding of identity work (Brown, 2020; Ybema et al, 2009) also focus on tensions and contradictions and the social processes around them, but while developing theory which has implications for learning this literature tends not to address learning directly. The papers in this special issue address this opportunity in different ways, each focusing on self-change and learning often in a social context which enables reflexivity.

We concur with Bridgman (2007) that it is important to connect critical analysis and engagement with practice and our analysis emphasizes the need to learn and act notwithstanding the contradictions and tensions that exist in organizations and with identities and relationships. The papers in this special issue highlight areas of decision and agency and situations when people's choices are limited through the operation of societal, organizational and managerial structures and discourses. Some of the contradictions and tensions addressed in this special issue are as follows. 
The identity and learning processes are both solo and collective. One way of addressing this contradiction is by arranging solo-reflexive and dialogical-social learning steps sequentially over time. Temporality can also be conceived in contradictory ways (see Weatherall and Ahuja, 2021) and in identity and learning there are advantages to avoiding a purely linear approach which assumes stepwise 'progress' by enabling both reflecting back by analysing experience and projecting forwards in planning for future action. There is also a potential contradiction between support and challenge and there can be a need for different learning spaces where an individual can be selfchallenging and can engage with others to work out how and where to act, resist or conform (or give the appearance of conformity). These processes are emotional and challenge the sense of self, including values (Hay, 2014), and the support of a group with sufficient similarity can be critical in building the psychological resources to persevere with the process and to explore difference. Such forms of interactive learning (Illeris, 2014) can be part of more formal learning in management programmes (Corlett et al., 2021) and give some structure to small group learning (Callagher et al., 2021) and interpersonal support for learning (Elraz and Knights, 2021; Weatherall and Ahuja, 2021).

We hope that the papers in this special issue will stimulate further research and dialogue as we believe the links between learning and identity as they relate to people in organizations is a field of inquiry with rich potential. Further research could pursue a number of directions. These include more analysis of equalities and diversity identity research as they relate to learning. For example, how learning has the potential to either constrain identity categorization and its consequences or help people resist or change such constraints. While some diversity categories and their intersectionality are discussed in the papers in this special issue (e.g. gender, ethnicity, sexuality and age) others (such as disabilities, faith and beliefs, class and socio-economic background) would also be valuable to explore further in organization and management studies. There is also relevance to the careers/HRM literatures, for example, in exploring the outcomes of the intersection of identity and learning for people's careers or organizational 'talent pipelines'. In this special issue, much of the analysis relates to informal learning. Further research could consider more formal approaches, for example qualification-based learning, the activities of business schools and, increasingly, the use of technologically enhanced learning which changes the dynamics described in some of the papers in this special issue where in-person interaction was important in enabling personal and group support in facing differences.

In addition to these potential lines of inquiry, there is an argument for both 'looking in' and 'looking out'. The learning and identities of others can be researched from an external perspective, but there are also opportunities to research 'from the inside'. The papers in this special issue typically incorporate qualitative and sometimes ethnographic work and there are opportunities for future research to build on this using auto-ethnographic and reflexive methods (see, e.g. Hibbert et al., 2021). We argue that there is an opportunity, and perhaps a responsibility, to take seriously how academic analysis can be influenced by and support developments in practice and policy. For example, work in this field could be relevant to current education policy debates on skills-oriented learning or equity and equalities in access to higher education, both of which are particularly important for business schools. Lastly, the papers in this special issue can be read as calling for empathy and compassion, and a challenge to management research and practice is to develop ways of legitimizing these in daily practice and organizational design.

This special issue identifies and engages with foundational questions of who we are, who we can be, how our learning processes and outcomes are part of this identity construction and what the consequences are for individuals and organizations. This is a substantial agenda that invites expansive learning and expansive research and consequently needs a networked community to undertake it. 


\section{Funding}

The author(s) received no financial support for the research, authorship, and/or publication of this article.

\section{ORCID iDs}

Nic Beech (iD) https://orcid.org/0000-0001-9182-6139

Christine Coupland (iD https://orcid.org/0000-0002-9357-1587

\section{References}

Alvesson M, Ashcraft KL and Thomas R (2008) Identity matters: Reflections on the construction of identity scholarship in organization studies. Organization 15: 5-28.

Armstrong SJ and Li Y (2017) A study of anglo expatriate managers' learning, knowledge acquisition, and adjustment in multinational companies in China. Academy of Management Learning and Education 16(1): $1-22$.

Ashforth BE and Mael F (1989) Social identity theory and the organization. Academy of Management Review 14: $20-39$.

Ashforth BE and Schinoff BS (2016) Identity under construction: How individuals come to define themselves in organizations. Annual Review of Organizational Psychology and Organizational Behavior 3: 111-137.

Bakhtin MM (1981) The Dialogical Imagination: Four Essays (ed M Holquist). Austin: University of Texas Press.

Bateson G (1972) Steps to an Ecology of Mind: Collected Essays in Anthropology, Psychiatry, Evolution and Epistemology. New York, NY: Ballentine Books.

Beech N (2017) Identity at work: An enquiry-based approach to therapeutically-inspired management. International Journal of Management Reviews 19(3): 357-370.

Beech N, Gilmore C, Hibbert P, et al. (2016) Identity-in-the-work and musicians' struggles: The production of self-questioning identity work. Work, Employment \& Society 30: 506-522.

Bell E and Bridgman T (2017) Why management learning matters. Management Learning 48(1): 3-6.

Blackler F and Regan S (2009) Intentionality, agency, change: Practice theory and management. Management Learning 40(2): 161-176.

Blumer H (1969) Symbolic Interactionism. Englewood Cliffs, NJ: Prentice-Hall.

Bolander P, Holmberg I and Fellbom E (2019) Learning to become manager: The identity work of first-time managers. Management Learning 50(3): 282-301.

Bridgman T (2007) Reconstituting relevance: Exploring possibilities for management educators' critical engagement with the public. Management Learning 38: 425-439.

Brown AD (2015) Identities and identity work in organizations. International Journal of Management Reviews 17: 20-40.

Brown AD (2017) Identity work and organizational identification. International Journal of Management Reviews 19: 296-317.

Brown AD (ed.) (2020) The Oxford Handbook of Identities in Organizations. Oxford: Oxford University Press.

Brown AD (2021) Identities in and around organizations: towards an identity work perspective. Human Relations. Epub ahead of print 24 February 2021. DOI: 10.1177/0018726721993910.

Brown AD, Lewis MA and Oliver N (2021) Identity work, loss and preferred identities: A study of UK business school deans. Organization Studies 42(6): 823-844.

Bryans P and Mavin S (2003) Women learning to become managers: Learning to fit-in or to play a different game? Management Learning 34(1): 111-134.

Burnham J, Palma DA and Whitehouse L (2008) Learning as a context for differences and differences as a context for learning. Journal of Family Therapy 30(4): 529-542.

Callagher LJ, El Sahn Z, Hibbert P, et al. (2021) The shelter and shadow of collective support. Management Learning [add details once published]. 
Caza BB, Vough H and Puranik H (2018) Identity work in organizations and occupations: Definitions, theories, and pathways forward. Journal of Organizational Behavior 39: 889-910.

Cerulo KA (1997) Identity construction: New issues, new directions. Annual Review of Sociology 23: 385409.

Corlett S, McInnes P, Coupland C, et al. (2017) Exploring the registers of identity research. International Journal of Management Reviews 19(3): 261-272.

Corlett S, Mavin S and Beech N (2019) Reconceptualising vulnerability and its value for managerial identity and learning. Management Learning 50(5): 556-575.

Corlett S, Ruane M and Mavin S (2021) Learning (not) to be different: The value of vulnerability in trusted and safe identity work spaces. Management Learning [add details when published].

Coupland C and Brown AD (2012) Identities in action: Processes and outcomes. Scandinavian Journal of Management 28: 1-4.

Coupland C, Cutcher L, Brown AD, et al. (2019) Identity and learning (not) to be different. Special Issue Call for Papers. Management Learning. https://journals.sagepub.com/pb-assets/Cfp\%20SI\%20Identities.pdf

Cunliffe AL (2002) Reflexive dialogical practice in management learning. Management Learning 33(1): $35-61$.

Cutcher L (2020) Conversations with the self and others: Practicing reflexive researcher identity work. In: Brown AD (ed.) The Oxford Handbook of Identities in Organizations. Oxford: Oxford University Press, 311-325.

DeRue DS and Ashford SJ (2010) Who will lead and who will follow? A social process of leadership identity construction in organizations. Academy of Management Review 35: 627-647.

Elraz H and Knights D (2021) Learning to manage a mental health condition: Caring for the self and 'normalizing' identity at work'. Management Learning. Epub ahead of print 22 April 2021. DOI: $10.1177 / 13505076211006618$.

Engeström Y (1987) Learning by Expanding: An Activity-Theoretical Approach to Developmental Research. Helsinki: Orienta-Konsultit.

Engeström Y (2018) Expansive learning: Toward an activity-theoretical reconceptualization. In: Illeris K (ed.) Contemporary Theories of Learning. London: Routledge. pp. 46-65.

Foucault M (1977) Discipline and Punishment: The Birth of the Prison. New York, NY: Vintage.

Gagnon S (2008) Compelling identity: Selves and insecurity in global, corporate management development. Management Learning 39(4): 375-391.

Giddens A (1991) Modernity and Self-Identity: Self and Identity in the Late Modern Age. Stanford, CA: Stanford University Press.

Greenberg D and Hibbert P (2020) COVID-19: Learning to hope and hoping to learn. Academy of Management Learning and Education 19(2): 123-130.

Greenwood M and Van Buren III HJ (2017) Ideology in HRM scholarship: Interrogating the ideological performativity of 'new unitarism'. Journal of Business Ethics 142(4): 663-678.

Greig G, Entwistle V and Beech N (2012) Addressing complex healthcare problems in diverse settings: Insights from activity theory. Social Science and Medicine 74(3): 305-312.

Greig G, Gilmore C, Patrick H, et al. (2013) Arresting moments in engaged management research. Management Learning 44(3): 267-285.

Handley K, Clark T, Fincham R, et al. (2007) Researching situated learning: Participation, identity and practices in client—consultant relationships. Management Learning 38(2): 173-191.

Hay A (2014) 'I don't know what I am doing!': Surfacing struggles of managerial identity work. Management Learning 45(5): 509-524.

Hibbert P, Beech N, Callagher L, et al. (2021) After the pain: Reflexive practice, emotion work and learning. Organization Studies. Epub ahead of print 30 April 2021. DOI: 10.1177/01708406211011014.

Ibarra H (1999) Provisional selves: Experimenting with image and identity in professional adaptation. Administrative Science Quarterly 44: 764-791.

Illeris K (2014) Transformative learning and identity. Journal of Transformative Education 12(2): 148-163.

Iszatt-White M, Kempster S and Carroll B (2017) An educator's perspective on reflexive pedagogy: Identity undoing and issues of power. Management Learning 48(5): 582-596. 
Leont'ev AN (1981) Problems of the Development of the Mind. Moscow: Progress.

Ligorio MB (2010) Dialogical relationship between identity and learning. Culture and Psychology 16(1): 93-107.

McDonald J (2013) Coming out in the field: A queer reflexive account of shifting researcher identity. Management Learning 44(2): 127-143.

Mead GH (1934) Mind, Self and Society, vol. 111. Chicago, IL: University of Chicago Press.

Phillips N and Hardy C (2002) Discourse Analysis: Investigating Processes of Social Construction. Thousand Oaks, CA: SAGE Publications.

Riach K and Cutcher L (2014) Built to last: Ageing, class and the masculine body in a UK hedge fund. Work, Employment and Society 28(5): 771-787.

Snow DA and Anderson L (1987) Identity work among the homeless: The verbal construction and avowal of personal identities. American Journal of Sociology 92(6): 1336-1371.

Thornborrow T and Brown AD (2009) 'Being regimented': Aspiration, discipline and identity work in the British Parachute Regiment. Organization Studies 30: 355-376.

Vough H, Caza BB and Maitlis S (2020) Making sense of myself: Exploring the relationship between identity and sensemaking. In Brown $\mathrm{AD}$ (ed.) The Oxford Handbook of Identities in Organizations. Oxford: Oxford University Press, 244-260.

Warhurst R (2011) Managers' practice and managers' learning as identity formation: Reassessing the MBA contribution. Management Learning 42(3): 261-278.

Watson TJ (2008) Managing identity: Identity work, personal predicaments and structural circumstances. Organization 15: 121-143.

Weatherall R and Ahuja S (2021) Learning as moments of friction and opportunity: An auto-ethnography of ECR identities in queer time. Management Learning [add details once published].

Ybema S, Keenoy T, Oswick C, et al. (2009) Articulating identities. Human Relations 62: 299-322. 